\title{
Interruption Duration Unit
}

National Cancer Institute

\section{Source}

National Cancer Institute. Interruption Duration Unit. NCI Thesaurus. Code C82585.

The unit of measure for the duration of an interruption in treatment. 